\title{
Prosexual Effect of Chrysactinia mexicana A. Gray (Asteraceae), False Damiana, in a Model of Male Sexual Behavior
}

\author{
R. Estrada-Reyes, ${ }^{1}$ O. A. Ferreyra-Cruz, ${ }^{1}$ G. Jiménez-Rubio, ${ }^{2}$ \\ O. T. Hernández-Hernández, ${ }^{3}$ and L. Martínez-Mota ${ }^{2}$ \\ ${ }^{1}$ Laboratorio de Fitofarmacología, Dirección de Investigaciones en Neurociencias, \\ Instituto Nacional de Psiquiatría Ramón de la Fuente Muñiz, Calzada México-Xochimilco 101, Col. San Lorenzo Huipulco, \\ Delegación Tlalpan, 14370 Ciudad de México, Mexico \\ ${ }^{2}$ Laboratorio de Farmacología Conductual, Dirección de Investigaciones en Neurociencias, \\ Instituto Nacional de Psiquiatría Ramón de la Fuente Muñiz, Calzada México-Xochimilco 101, Col. San Lorenzo Huipulco, \\ Delegación Tlalpan, 14370 Ciudad de México, Mexico \\ ${ }^{3}$ CONACYT Research Fellow, Instituto Nacional de Psiquiatría, Ciudad de México, Mexico
}

Correspondence should be addressed to L. Martínez-Mota; lucia@imp.edu.mx

Received 28 April 2016; Revised 24 July 2016; Accepted 10 August 2016

Academic Editor: Ruxana Sadikot

Copyright (C) 2016 R. Estrada-Reyes et al. This is an open access article distributed under the Creative Commons Attribution License, which permits unrestricted use, distribution, and reproduction in any medium, provided the original work is properly cited.

\begin{abstract}
Chrysactinia mexicana A. Gray (Asteraceae) and Turnera diffusa Willd (Turneraceae) are employed in traditional medicine as aphrodisiacs; however, there is no scientific evidence supporting the prosexual properties of C. mexicana. The aim of this study was to determine whether an aqueous extract of $C$. mexicana $(\mathrm{Cm})$ stimulates rat male sexual behavior in the sexual exhaustion paradigm. Sexually exhausted (SExh) male rats were treated with $\mathrm{Cm}(80,160$, and $320 \mathrm{mg} / \mathrm{kg}$ ), an aqueous extract of T. diffusa (Td), or yohimbine. The sexual exhaustion state in the control group was characterized by a low percentage of males exhibiting mounts, intromissions, and ejaculations and no males demonstrating mating behavior after ejaculation. Cm ( $320 \mathrm{mg} / \mathrm{kg}), \mathrm{Td}$, or yohimbine significantly increased the proportion of SExh rats that ejaculated and resumed copulation after ejaculation. In males that exhibited reversal of sexual exhaustion, $\mathrm{Cm}(320 \mathrm{mg} / \mathrm{kg})$ improved sexual performance by reducing the number of intromissions and shrinking ejaculation latency. The effects of treatments on sexual behavior were not related with alterations in general locomotion. In conclusion, the prosexual effects of $\mathrm{Cm}$, as well as those of $\mathrm{Td}$, are established at a central level, which supports the traditional use of C. mexicana for stimulating sexual activity.
\end{abstract}

\section{Introduction}

Sexual interaction is an important factor for social and biological relationships in human life. Alterations in sexual activity may affect not only the health, but also the quality of human life. Studies carried out in the U.S. have estimated that up to $52 \%$ of men between ages 40 and 70 years of age suffer from some alterations of sexual health due to aging or resulting from medical conditions such as diabetes, stress, hypertension, or obesity [1]. In this case, medicinal plants comprise an alternative for improving sexual health, facilitating aspects of sexual performance, and increasing the libido [2]. This information derives from ethnomedical reports, which attribute prosexual effects to a group of plants, although scientific information of their pharmacological properties is not widely published.

Within the context of traditional medicine, the term "aphrodisiac" is given to any substance (i.e., food, beverages, or drugs) capable of stimulating the libido or sexual activity [3]. Investigation suggests that these substances may act at the level of the Central Nervous System (CNS) by altering specific neurotransmitters or sex hormones [3]. In this respect, herbal preparations considered as aphrodisiacs in traditional medicine may produce their effects by stimulating targets in the CNS. C. mexicana is a plant used in Mexican traditional medicine to treat a number of diseases, such as respiratory 
diseases, skin infections, and rheumatism, and as a diuretic and spasmolytic agent [4]. However, it is primarily used as a stimulating agent and as a "powerful aphrodisiac" to improve libido in males $[5,6]$. In North America, C. mexicana is widely distributed from New Mexico and Texas south to central Mexico, including Chihuahua, Nuevo León, Durango, Zacatecas, Aguascalientes, San Luis Potosí, Guanajuato, Mexico City (CDMX), Hidalgo, Puebla, Veracruz, and Oaxaca. Due to its putative aphrodisiac properties, C. mexicana is highly consumed and commercialized in North America and some countries of South America.

C. mexicana is known as Damiana, Damianita, or false Damiana due to its morphological resemblance to "Damiana de California" (Turnera diffusa Willd, Turneraceae) and "garañona", in reference to its proposed prosexual effects $[5,7]$. Both species share the yellow color of their flowers and fragrance, but they possess morphological differences, that is, shape of leaves and stems. In both species, there is also chemical similarity, that is, apigenin, and its glucoside derivatives are present in each in significant amounts. However, unlike C. mexicana, T. diffusa has been identified as a plant with properties that stimulate sexual activity in different experimental models. Crude extracts of T. diffusa have been proven to stimulate sexual behavior in male rats classified as sexually sluggish, that is, those with slower copulation that requires more intromissions to reach the ejaculatory threshold. In these animals, extracts of $T$. diffusa reduced ejaculatory latency $[8,9]$. Besides, in a previous study, we showed that a standardized aqueous extract of $T$. diffusa improved sexual behavior in sexually exhausted (SExh) male rats, reversing the inhibition of sexual behavior presented by these animals [10]. Sexual exhaustion (also denominated sexual satiation) is considered a paradigm of the central inhibition of male sexual behavior [11], which led us to propose that the extract of $T$. diffusa stimulates copulation by stimulating brain targets that participate in male sexual behavior.

Sexual exhaustion in male rats is a phenomenon that appears after sustained copulation with a single sexually receptive female. Sexual satiation has been mainly studied in male rats, and males of other mammalian species, such as hamster [12], guinea pig [13], rabbit [14], and Rhesus macaque [15] demonstrated similar behavior after sustained sexual activity. The standard protocol of sexual exhaustion in rats consists of free copulation during a $4 \mathrm{~h}$ period during which male rats achieve a mean of seven ejaculations [16]. There is evidence that copulation to satiation induces physiological changes that include transient modifications in brain functions [17, 18]. Thus, $24 \mathrm{~h}$ after ad libitum mating behavior, males present an inhibition of sexual behavior that can last up to $96 \mathrm{~h}[11,19]$. Several pharmacological studies have shown that sexual exhaustion is reversed by drugs that affect different neurotransmiter systems, such as the serotonergic (i.e., with the $5-\mathrm{HT}_{1 \mathrm{~A}}$ agonist, 8-OH-DPAT), noradrenergic (i.e., with the $\alpha 2$-adrenergic antagonist, yohimbine), and the glutamatergic (i.e., with antagonists of the NMDA, AMPA, and mGluR5 receptor subtypes) systems, which restore the expression of copulatory behavior [16, 23, 24, 27, 29]. Regarding the effects of T. diffusa, our previous findings support the fact that the sexual exhaustion paradigm is a good predictive model for the study of plants with putative aphrodisiac properties [10].

The aim of this research was to evaluate the prosexual effects of a standardized aqueous extract of C. mexicana $(\mathrm{Cm})$ in SExh male rats. The actions of this extract were compared with those produced by a standardized aqueous extract of $T$. diffusa (Td) and yohimbine, employed as a reference drug for the reversal of sexual satiation [20]. Additionally, the effects of treatments in the Open Field Test (OFT) were determined for discarding nonspecific effects (i.e., changes in locomotor and general activity) that could affect the interpretation of results in the sexual behavior test.

\section{Materials and Methods}

2.1. Animals. Adult male $(n=69 ; 300 \mathrm{~g}$ body weight $(\mathrm{BW}))$ and female ( $n=40 ; 200 \mathrm{~g} \mathrm{BW)} \mathrm{Wistar} \mathrm{rats} \mathrm{(obtained} \mathrm{from} \mathrm{the}$ Vivarium of the Instituto Nacional de Psiquiatría "Ramón de la Fuente Muñiz" in Mexico City) were used in this study. Rats were housed (five animals per cage according to sex, $53 \times 43$ $\times 20 \mathrm{~cm}$ ) in independent rooms with an inverted $12-\mathrm{h}: 12-\mathrm{h}$ light/dark cycle (lights on 22:00 h) and controlled conditions of temperature and humidity. Rats had free access to water and food during all experiments. Animal management was conducted according to the specifications of Mexican Official Norm (NOM-062-ZOO-1999) and the General Principles of Laboratory Animal Care (U.S. National Institutes of Health (NIH) publication \#85-23, revised in 1985). The protocol was approved by the local Ethics Committee.

\subsection{Vegetal Material and Preparation of the Aqueous Extract.} Chrysactinia mexicana A. Gray (Asteraceae) aerial parts were collected in State of Morelos, Mexico. The aerial parts of Turnera diffusa Willd (Turneraceae) were collected in the State of Hidalgo, Mexico (voucher nos. 14407 and 11486, resp.). The aqueous extracts evaluated here were obtained and chemically characterized previously by our work group $[10,21,22]$. Briefly, aerial parts of either species were air-dried and finely ground to prepare the aqueous extract with $10 \mathrm{~g}$ of vegetal material per $90 \mathrm{~mL}$ of boiling, distilled water and heated for $10 \mathrm{~min}$. The extract was allowed to cool at room temperature, filtered, and dried in a Telstar Freezer Dryer at $-50^{\circ} \mathrm{C}$ and $0.01 \mathrm{mBar}$. The yield was $17.6 \%$ for $\mathrm{Cm}$ and $20 \%$ for Td of dried aqueous extracts, which were stored at $-4^{\circ} \mathrm{C}$.

2.3. Treatments and Experimental Design. Aqueous extracts $(\mathrm{Cm}$ and $\mathrm{Td})$ were dissolved in saline $0.9 \%$ solution with one drop of Tween 80; this later solution was used as vehicle (Sigma-Aldrich, St. Louis, MO, USA), while yohimbine (Sigma-Aldrich) was dissolved in saline solution.

Independent groups of SExh males were per os (p.o.) treated with the Cm extract at $80(n=7), 160(n=10)$, and $320(n=11) \mathrm{mg} / \mathrm{kg}$ or the vehicle $(n=20), 60 \mathrm{~min}$ prior to starting the test. Doses were chosen in pilot studies carried out at our laboratory. Other groups of SExh males 
were treated with $\mathrm{Td}(80 \mathrm{mg} / \mathrm{kg}$; p.o., $n=11 ; 60 \mathrm{~min}$ before the test) or yohimbine ( $2 \mathrm{mg} / \mathrm{kg}$; i.p., $n=10 ; 30 \mathrm{~min}$ before the test); these doses have been reported to reverse the sexual inhibition of sexually satiated males [10, 23].

\subsection{Sexual Behavior Evaluation}

2.4.1. Training of Sexual Behavior. Male rats were trained for sexual experience in five sessions, one session per week, with sexually receptive females. For induction of receptivity, ovariectomized female rats were treated in a sequential manner with estradiol benzoate (Sigma-Aldrich, St. Louis, MO, USA; $4 \mu \mathrm{g} / \mathrm{rat}$, subcutaneously (s.c.)) and progesterone (Sigma-Aldrich; $2 \mathrm{mg} /$ rat, s.c.) 48 and 4 h, respectively, prior to each evaluation of sexual behavior.

Training sessions were carried out in polycarbonate cylindrical cages $(60 \mathrm{~cm} \times 40 \mathrm{~cm})$, under dim red light conditions, $3 \mathrm{~h}$ after the beginning of the photoperiod dark phase. Males were allowed to copulate until they achieved ejaculation in a 30 min session. Males that accomplished sexual behavior achieving ejaculation in a period of $<15 \mathrm{~min}$ in at least three training sessions were considered sexually experienced and were subjected to sexual exhaustion.

2.4.2. Sexual Exhaustion Paradigm. One week after the last sexual behavior training, sexually experienced males were allowed to freely copulate during a $4 \mathrm{~h}$ period with a single sexually receptive female. According to previous reports using this procedure [16], the sexual exhaustion state was confirmed by a period of 90 min without expression of male sexual behavior.

2.4.3. Sexual Behavior Test. Twenty four h after copulation ad libitum, males were treated and evaluated in a standard sexual behavior test with a maximal length of $30 \mathrm{~min}$. A novel sexually receptive female was used to stimulate sexual behavior in males. The sexual behavior test was immediately finished after the following: (a) the occurrence of the first copulatory series in the 30 min test: a copulatory series includes the ejaculatory series (from the first mount or intromission to ejaculation) plus the subsequent first intromission; (b) if ejaculation latency exceeded $30 \mathrm{~min}$; or (c) if males did not express sexual behavior within $20 \mathrm{~min}$. Two observers quantified three components of male sexual behavior: (a) mounts, defined as pelvic thrusting without intravaginal penile insertion; (b) intromissions, defined as pelvic thrusting with intravaginal penile insertion, and (c) ejaculation, pelvic thrusting with intravaginal expulsion of seminal contents. These observations were employed to calculate the percentage of animals that expressed mounts, intromissions, ejaculations, and resumption of copulation, as well as the total number of mounts (NM) and intromissions (NI) that preceded ejaculation; intromission latency (time from introduction of female to experimental cage to the occurrence of the first intromission, IL), ejaculation latency (time from the first intromission to male achieving ejaculation, EL), and postejaculatory interval (time from ejaculation to first intromission of a second ejaculatory series, PEI).
Results were expressed as mean \pm standard error of the mean (SEM).

The effect of treatments on male sexual behavior within the context of sexual satiation was interpreted according to Rodríguez-Manzo [24]. Facilitation of the expression of male sexual behavior was reported when treatments increased the proportion of males able to execute mounts and intromissions and to achieve ejaculation. Reversal of sexual exhaustion was determined by a significant increase in the percentage of rats able to resume copulation after ejaculation (from the beginning of copulation taking the first intromission into account). Additionally, improvement of sexual performance was determined by a reduction in NM and NI and a shortening of IL, EL, and PEI.

2.5. Open Field Test (OFT). In order to discard possible unspecific effects due to drugs, actions of treatments on ambulation were evaluated in an OFT. One week after the final sexual behavior evaluation, male rats were randomly assigned to the treatments ( $n=6$ rats per group) following a Latin square design, in which each rat has the same opportunity to receive any treatment. One $\mathrm{h}$ after drug administration, the rats were tested in a Plexiglass cage with the floor divided into 12 equal squares. The number of squares that animals crossed during a $5 \mathrm{~min}$ period was recorded by two trained observers. Results were expressed as mean number of counts \pm SEM.

2.6. Statistics. The proportion of copulating animals was analyzed utilizing the Fisher F-test. Data that meet the criteria of linearity and equality of variance were analyzed using parametric tests, while data that did not meet them were analyzed with nonparametric tests. Effect of $\mathrm{Cm}$ on the specific parameters of sexual behavior, that is, EL, was analyzed with a Kruskal-Wallis test followed by Dunn's test. Paired comparisons between each dose of $\mathrm{Cm}$ or vehicle versus $\mathrm{Td}$ or yohimbine were carried out with a Mann Whitney $U$ test. Effect of $\mathrm{Cm}$ on ambulatory activity was analyzed with a one-way ANOVA followed by the correction of Bonferroni. Paired comparisons between each dose of $\mathrm{Cm}$ or vehicle versus $\mathrm{Td}$ or yohimbine were carried out with a Mann Whitney $U$ test.

\section{Results}

Twenty four h after prolonged copulation, sexually satiated males of the control group (rats treated with the vehicle) showed an inhibition of sexual behavior determined by a reduction in the number of subjects able to demonstrate regular sexual behavior. We found that $<45 \%$ of the control group population exhibited mounts and intromissions, while only $35 \%$ of this group was able to achieve one ejaculation (Table 1). None of these SExh males was able to restart copulation after the single ejaculation.

Treatments utilized here stimulated SExh males to engage in one or more behaviors within the context of copulation. Male rats treated with $\mathrm{Cm}$ or $\mathrm{Td}$ extracts or yohimbine exhibited a normal pattern of movements during the course 
TABLE 1: Effect of the treatments on the number and percentage (\%) of sexually exhausted male rats that expressed sexual behavior.

\begin{tabular}{lcccc}
\hline Treatments & Mounts & Intromissions & Ejaculation & Resuming \\
\hline Vehicle, $n=20$ & $9(45)$ & $7(35)$ & $7(35)$ & $3(43)$ \\
Cm $80 \mathrm{mg} / \mathrm{kg}, n=7$ & $3(43)$ & $3(43)$ & $6(60)$ & $1(14.3)$ \\
$\mathrm{Cm} 160 \mathrm{mg} / \mathrm{kg}, n=10$ & $6(60)$ & $6(60)$ & $10(90.9)$ & $1(10)$ \\
$\mathrm{Cm} 320 \mathrm{mg} / \mathrm{kg}, n=11$ & $11(100)$ & $11(100)$ & $10(90.9)$ & $6(54.5)$ \\
Td $80 \mathrm{mg} / \mathrm{kg}, n=11$ & $9(81.8)$ & $8(72.7)$ & $10(100)$ & $7(63.6)$ \\
Yoh $2 \mathrm{mg} / \mathrm{kg}, n=10$ & $10(100)$ & $10(100)$ & $100)$ \\
\hline
\end{tabular}

Left side of the table depicts the total number of subjects that were assigned to each group of treatment before the session of ad libitum copulation. Columns of the right side depict the number (and percentage) of sexually exhausted males that showed mounts, intromissions, and ejaculation or that resumed copulation in the test of sexual behavior. Treatments were administered $24 \mathrm{~h}$ after ad libitum copulation, and $1 \mathrm{~h}$ before the sexual behavior test. An aqueous extract of $C$. mexicana $(\mathrm{Cm})$; an aqueous extract of T. diffusa (Td) and yohimbine (Yoh).

of copulation, which was not different from that shown by satiated males receiving the vehicle, or even from sexually experienced males (observations from the same males prior to the sexual exhaustion test). Thus, treated rats did not exhibit hyper- or hypoactivity nor stereotyped or circling movements in the sexual behavior test as compared with those treated with vehicle. In this evaluation, it was observed that the medium dose of $\mathrm{Cm}(160 \mathrm{mg} / \mathrm{kg})$ produced a slight increase in the number of SExh subjects that could copulate until reaching ejaculation, although this effect did not attain statistical significance with respect to the vehicle control group (Figure 1). Clearly, the highest dose of $\mathrm{Cm}(320 \mathrm{mg} / \mathrm{kg}$ ) significantly increased the proportion of rats that exhibited mounts, intromissions, and ejaculation. This latter dose also increased the proportion of males that restarted copulation after ejaculation. The effect of $\mathrm{Cm}$ on the expression of sexual behavior was doses-dependent in the percentage of animals that executed mounts and intromissions.

Regarding comparison among drugs, we found that the proportion of sexually satiated males that intromitted and ejaculated was similar under the treatment with $\mathrm{Cm}$ $(320 \mathrm{mg} / \mathrm{kg}), \mathrm{Td}$, and yohimbine. In animals demonstrating mounts, such equivalence was found in the groups treated with $\mathrm{Cm}(320 \mathrm{mg} / \mathrm{kg})$ and yohimbine. Regarding the percentage of animals that resumed sexual behavior, $\mathrm{Cm}(320 \mathrm{mg} / \mathrm{kg})$ and $\mathrm{Td}$ produced similar effects. As expected, yohimbine produced the maximal effect on male sexual behavior, since $100 \%$ of treated animals showed mounts and intromissions, reached ejaculation, and resumed copulation.

Analysis of the specific parameters of male sexual behavior was performed only in SExh rats that exhibited sexual behavior. Treatment with $\mathrm{Cm}$ produced no significant effects on IL $(H=0.18$, df $3, p=0.98)$, NM $(H=1.10$, df $3, p=0.77)$ (Table 2$)$, and NI $(H=5.90$, df $3, p=0.11)$ (Figure 2(a)). However, paired comparisons showed that Td increased the NI with respect to the highest dose of $\mathrm{Cm}(320 \mathrm{mg} / \mathrm{kg})$. Td did not increase the NI with respect to the vehicle control group (Figure 2(a)). Treatment with $\mathrm{Cm}$ significantly reduced the EL $(H=8.64$, df $3, p=0.034$; Figure 2(b)) of SExh males, reaching the statistical significance with that higher dose of $\mathrm{Cm}(320 \mathrm{mg} / \mathrm{kg})$ with respect to the vehicle control group.

In the vehicle-control group, no satiated male was able to normally copulate with fresh, sexually receptive females. This

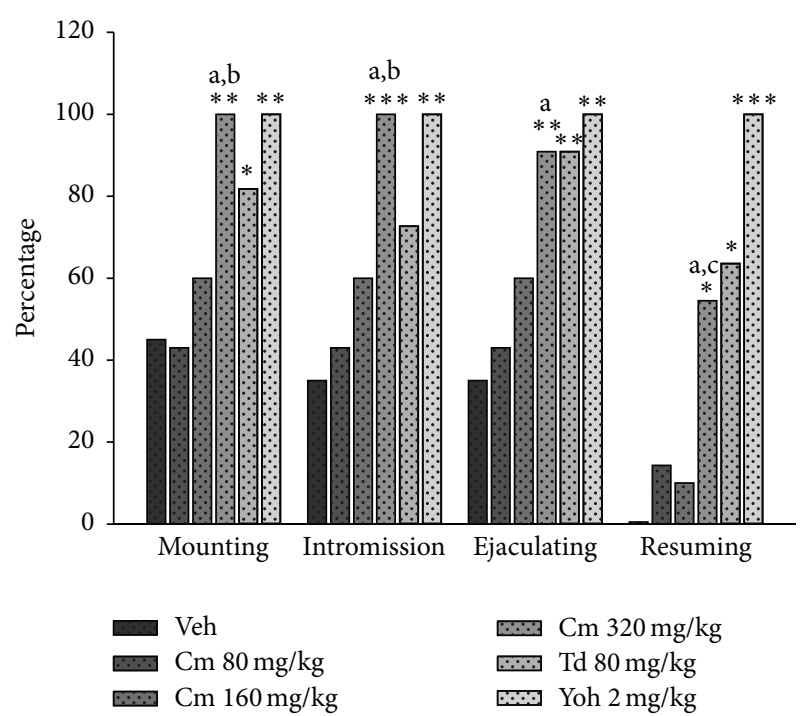

FIGURE 1: Effect of an aqueous extract of C. mexicana $(\mathrm{Cm})$, T. diffusa (Td), or yohimbine (Yoh) on the percentage of sexually exhausted males that display sexual behavior. Results of the Fisher $F$-test: ${ }^{*} p<$ $0.05 ;{ }^{* *} p<0.01 ;{ }^{* * *} p<0.001$ versus the vehicle (Veh) control group; (a) $p<0.05$ versus $\mathrm{Cm} 80 \mathrm{mg} / \mathrm{kg}$ group; (b) $p<0.05$ versus $\mathrm{Cm} 160 \mathrm{mg} / \mathrm{kg}$ group; (c) $p<0.01$ versus $\mathrm{Cm} 160 \mathrm{mg} / \mathrm{kg}$.

TABLE 2: Effect of the treatments on the number of mounts and intromission latency of sexually exhausted males rats that expressed sexual behavior.

\begin{tabular}{lcc}
\hline Treatments & Number of mounts & Intromission latency $(\mathrm{sec})$ \\
\hline Veh & $9.33 \pm 2.35$ & $60.75 \pm 12.17$ \\
$\mathrm{Cm} 80 \mathrm{mg} / \mathrm{kg}$ & $12.66 \pm 6.06$ & $91.33 \pm 50.54$ \\
$\mathrm{Cm} 160 \mathrm{mg} / \mathrm{kg}$ & $10.00 \pm 3.89$ & $63.83 \pm 23.03$ \\
$\mathrm{Cm} 320 \mathrm{mg} / \mathrm{kg}$ & $8.76 \pm 3.44$ & $239.76 \pm 131.50$ \\
$\mathrm{Td} 80 \mathrm{mg} / \mathrm{kg}$ & $16.10 \pm 2.43$ & $79.87 \pm 17.48$ \\
Yoh $2 \mathrm{mg} / \mathrm{kg}$ & $3.50 \pm 0.60$ & $45.70 \pm 10.71$ \\
\hline
\end{tabular}

Data are expressed as mean \pm S.E.M and the total number of subjects that were assigned to each group of treatment. An aqueous extract of $C$. mexicana $(\mathrm{Cm})$; an aqueous extract of T. diffusa (Td) and yohimbine (Yoh).

means that males exhibited a sexual exhaustion state and that their PEI could be as long as $72 \mathrm{~h}$ [11]. Thus, the effects of 


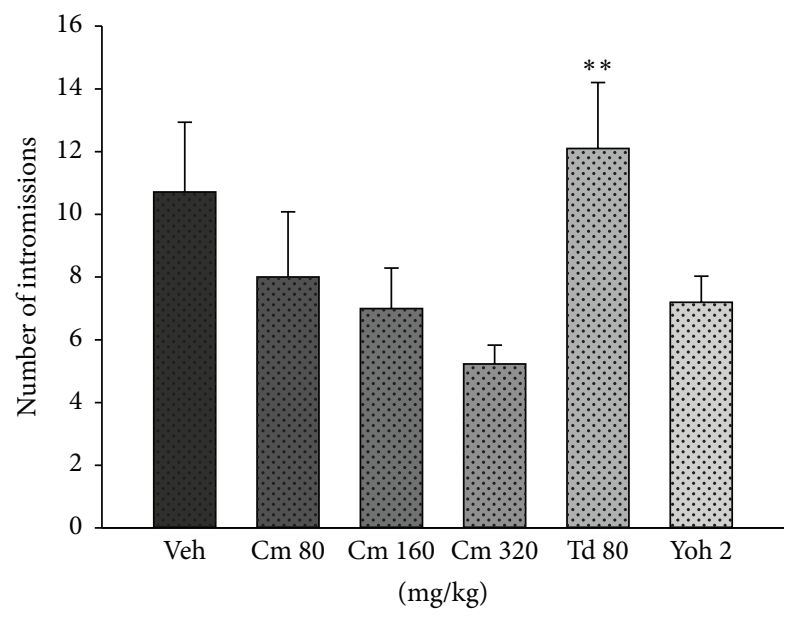

(a)

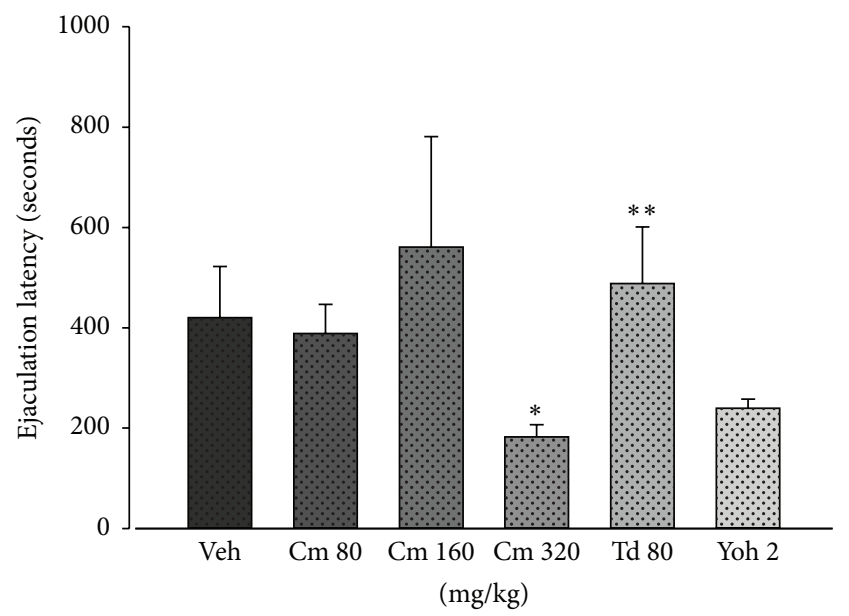

(b)

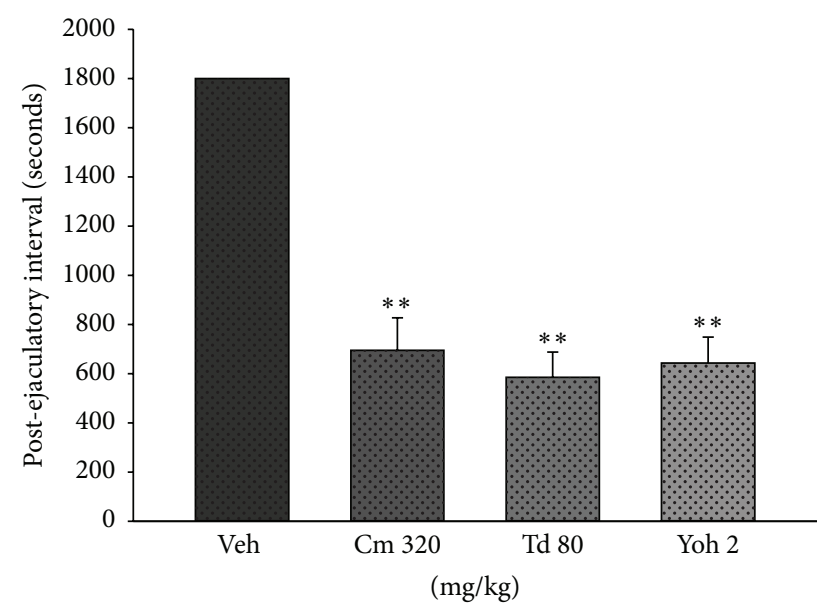

(c)

Figure 2: Effect of an aqueous extract of C. mexicana (Cm), T. diffusa (Td), or yohimbine (Yoh) on the number of intromissions (a), ejaculation latency (b), and postejaculatory interval (c) of sexually exhausted males that showed sexual behavior. Data of IPE were compared against an arbitrary value corresponding to the total time for a sexual behavior test. Results are expressed as mean \pm S.E.M. Paired comparisons in groups treated with Cm were done with Dunn's test. Other comparisons were done with the Mann Whitney $U$ test: in (a) ${ }^{*} p<0.05$ versus vehicle (Veh), ${ }^{* *} p<0.01$ versus Cm $320 \mathrm{mg} / \mathrm{kg}$; in (b) ${ }^{*} p<0.05$ versus Veh, ${ }^{* *} p<0.01$ versus $\mathrm{Cm} 320 \mathrm{mg} / \mathrm{kg}$; in $(\mathrm{c}){ }^{* *} p<0.01$ versus Veh.

the treatments on PEI (Figure 2(c)) were compared versus an arbitrary value corresponding to the total evaluation time in the standard sexual behavior test $(1,800 \mathrm{sec})$. Under these conditions, paired comparisons showed that $\mathrm{Cm}$ at higher dose, $\mathrm{Td}$, and yohimbine significantly reduced the PEI regarding this arbitrary value. Medium and lower doses of $\mathrm{Cm}$ were not included in the analysis, because only one subject per group was able to resume copulation after ejaculation.

Treatment with $\mathrm{Cm}$ produced significant changes $(F=$ 5.70 , df $3, p=0.005$, Table 3 ) on the ambulatory activity evaluated in the OFT. Lower dose $(80 \mathrm{mg} / \mathrm{kg})$ of Cm increased the ambulatory activity and this effect was statistically different with respect to the same extract at $160 \mathrm{mg} / \mathrm{kg}$ or with respect to Td. Effect of $\mathrm{Cm}$ at lower dose was not significantly different from the vehicle control group. In this test treatments did not induce alterations in general motor activity, that is, stereotypes or circling behavior.

\section{Discussion}

Many herbal therapies show some potential benefits in improving male sexual function [25]; however, the therapeutic potential of these medicinal plants requires the support of the scientific evidence for validating their putative effects and safety. Our results represent the first evidence that an aqueous extract of C. mexicana is able to improve sexual behavior expression in male rats exhibiting transient inhibition of sexual activity.

Animal models to evaluate male sexual behavior in the laboratory usually constituted of rodents expressing different levels of sexual activity, such as sexually experienced or sluggish rats, which have shorter or longer ejaculation latencies, among other features [26]. On the other hand, the main feature of the sexual exhaustion paradigm is the central inhibition of male sexual behavior stimulated by repeated copulation with a single sexually receptive female $[16,23,27]$. 
TABLE 3: Effect of the treatments in male rats evaluated in the OFT.

\begin{tabular}{lc}
\hline Treatment & Number of counts/5 min \\
\hline Vehicle & $41.83 \pm 3.05$ \\
$\mathrm{Cm} 80 \mathrm{mg} / \mathrm{kg}$ & $60.50 \pm 3.47$ \\
$\mathrm{Cm} 160 \mathrm{mg} / \mathrm{kg}$ & $31.16 \pm 5.35^{* *}$ \\
$\mathrm{Cm} 320 \mathrm{mg} / \mathrm{kg}$ & $44.00 \pm 7.32$ \\
$\mathrm{Td} 80 \mathrm{mg} / \mathrm{kg}$ & $34.16 \pm 4.81^{* *}$ \\
Yoh $2 \mathrm{mg} / \mathrm{kg}$ & $45.16 \pm 3.57$ \\
\hline
\end{tabular}

Rats were treated with aqueous extracts of C. mexicana $(\mathrm{Cm})$, T. diffusa (Td), or yohimbine (Yoh). Data are expressed as mean \pm S.E.M. Paired comparisons in groups treated with $\mathrm{Cm}$ were done with the correction of Bonferroni. Other comparisons were done with the Mann Whitney $U$ test. ${ }^{* *} P<0.01$ versus $\mathrm{Cm}$ at $80 \mathrm{mg} / \mathrm{kg}$.

According to the literature, sexual satiation involves three phases [28]. During the first phase, the majority of male rats (>92\%) copulating ad libitum display a minimum of six ejaculations before reaching sexual satiety. This phase is followed by the phase involving the installation of sexual satiation, which requires a period of $24 \mathrm{~h}$, during which brain plastic changes take place. The third phase is characterized by inhibition of sexual behavior during which only $30 \%$ of the SExh population can achieve a single ejaculation without restarting sexual activity after this. Results of the present study are in agreement with this information, in that the sexually competent males utilized for our experiment presented all phases until reaching the sexual exhaustion state by means of free copulation. Once satiety was installed, only $35 \%$ of the SExh population was able to achieve a single ejaculation, while no rat resumed copulation after ejaculation. The literature reports that this inhibition is well established during $24 \mathrm{~h}$ period after ad libitum mating behavior [11], whereby we used this period to evaluate the possible prosexual effects of $\mathrm{Cm}$ associated with its interaction with central targets in the nervous system.

Current experiments revealed that in SExh males the treatment with an aqueous extract of $C$. mexicana produces stimulant effects on sexual behavior. It was found that the medium dose of the extract $(160 \mathrm{mg} / \mathrm{kg})$ slightly increased the number of rats that showed mounts and intromissions and that attained threshold for ejaculating once. These effects attained the statistical significance with $\mathrm{Cm}$ at $320 \mathrm{mg} / \mathrm{kg}$; therefore, this aqueous extract, at the highest dose employed herein, favored the expression of the male sexual behavior of SExh animals. Furthermore, this dose of $\mathrm{Cm}$ also increased by $54 \%$ the proportion of males that resumed copulation with respect to the control group (0\%). According to the interpretation of sexual exhaustion paradigm and its regulation by drugs, a treatment is considered to reverse sexual satiety if it significantly increases the proportion of males that achieve ejaculation and resume copulation after ejaculation [16]. This pharmacological effect is produced by an ample number of drugs that affect different neurotransmitter systems [11, 29, 30]. In agreement with these, the present results provide evidence that the standardized extract of $\mathrm{Cm}$ at a high dose produces the reversal of sexual exhaustion state.

In traditional medicine, C. mexicana and T. diffusa are used interchangeably for improving sexual activity based on their botanical resemblance $[7,31]$. Therefore, in the present study, the prosexual effects of $\mathrm{Cm}$ were compared with those of Td and yohimbine, employed as a reference drug with known effects on sexual exhaustion [20]. Our results demonstrated that both extracts improved the expression of sexual behavior in an equivalent manner, that is, allowing $90.9 \%$ of the population of satiated males to achieve ejaculation. The extracts also produced similar effects on the reversal of sexual satiation, because $\mathrm{Cm}$ increased the percentage of SExh males that resumed sexual activity at $54.5 \%$, while Td did so at $63.6 \%$. These results showed that the effective dose of $\mathrm{Cm}$ for reversal of sexual exhaustion was threetimes higher $(320 \mathrm{mg} / \mathrm{kg})$ than that of $\mathrm{Td}(80 \mathrm{mg} / \mathrm{kg})$. This difference in pharmacological potency may have implications for the ethnomedical use of species as aphrodisiac remedies. As expected, yohimbine at $2 \mathrm{mg} / \mathrm{kg}$ was the most effective drug for promoting the resumption of copulation in SExh rats. This result agrees with data from previous literature demonstrating the high efficacy of yohimbine in the reversal of sexual satiation [16]. Differences in the effective treatment doses utilized here for the reversal of sexual satiation could be explained taking into account that yohimbine is a pure drug, while crude extracts are constituted of multiple components $[10,21]$ of which their pharmacokinetic and pharmacodynamics are unknown.

In relation to the sexual performance of SExh rats that recovered sexual activity, only $\mathrm{Cm}$ at the highest dose $(320 \mathrm{mg} / \mathrm{kg})$ produced further effects on male sexual behavior, reducing NI and shortening EL. Consistently, Cm $(320 \mathrm{mg} / \mathrm{kg}), \mathrm{Td}$, and yohimbine produced a reduction of the PEI of sexually exhausted males, in comparison with an arbitrary value corresponding to total time of test. This value was established considering that satiated control-group were unable to resume copulation during the test and that the reestablishment of normal sexual activity could take $>72 \mathrm{~h}$ after free copulation [11]. Then, in addition to the effects of $\mathrm{Cm}$ on the expression of sexual behavior, this extract at a high dose also improved the sexual performance of SExh males that recovered their ability to copulate.

The effects of $C$. mexicana shown here suggest that the constituents of this plant produce their stimulating effects by acting on central targets participating in the reversal of sexual exhaustion. A number of studies has demonstrated that the mesolimbic system comprises a fundamental target for installation of sexual satiation in males. The mesolimbic system is composed of mesencephalic structures, such as the ventral tegmental area (VTA), which contains dopaminergic neurons that send projections to limbic structures such as the nucleus accumbens (NAc). This system participates in providing rewards for natural (or artificial) stimuli, such as food and sexual activity [32]. It has been demonstrated that drugs facilitating dopaminergic transmission in the mesolimbic pathway reverse the sexual exhaustion [29]. These facts suggest that the constituents of $\mathrm{Cm}$ may engage in an interaction with dopaminergic system in the mesolimbic pathway. The comparison of the effects of $\mathrm{Cm}$ with those of yohimbine in the reversal of sexual satiation reinforces this idea. Yohimbine acts as an antagonist of $\alpha 2$-adrenergic receptors to increase noradrenaline release; this mechanism 
has been associated with the reversal of sexual exhaustion elicited by this drug [16]. In addition, it has been shown that the combination of subthreshold doses of apomorphine, a dopaminergic agonist, synergizes with subthreshold doses of yohimbine, to reverse sexual exhaustion. The simultaneous injection of haloperidol, a nonspecific dopamine receptor antagonist, with yohimbine, interferes with actions of the latter on sexual exhaustion [20]. Therefore, dopamine has been proposed as a crucial neurotransmitter in the action of yohimbine on sexual satiation [20]. Taking these data together, it is possible to suggest that the prosexual actions of $\mathrm{Cm}$ in SExh males are produced by changes in dopaminergic transmission in the mesolimbic system. This proposal is further supported by the results of sexual performance, although the actions of yohimbine on EL and NI were weaker than those elicited by $\mathrm{Cm}$.

Stimulation of male sexual behavior by drugs could be associated with an increase in general locomotor activity. In the sexual behavior test, satiated males treated with the extracts of $\mathrm{Cm}$ and $\mathrm{Td}$ or with yohimbine exhibited a normal pattern of movement in the course of copulation, which was not different from that shown by males receiving the vehicle; that is, these rats did not demonstrate hyper- or hypoactivity nor stereotyped or circling movements. Results obtained in the OFT agree with these observations. Lower and medium doses of $\mathrm{Cm}$ were ineffective for restoring mating behavior, and only the lowest dose of $\mathrm{Cm}$ increased the ambulation of experimental animals. Additionally, the effective doses of $\mathrm{Cm}, \mathrm{Td}$, and yohimbine on sexual behavior test were not associated with stimulating motor effects. It can be suggested that there is no association between the actions of treatments on sexual activity and ambulatory activity.

It has been extensively documented that sexually satiated rats exhibit generalized hypersensitivity to drugs acting on different neurotransmitter systems [33]. The present data cannot preclude that doses of Cm higher than $320 \mathrm{mg} / \mathrm{kg}$ produce motor alterations; however, in addition to the quantitative evaluation, treatments and doses that stimulated sexual behavior did not produce undesirable effects in the OFT. Even more so, we do not have sufficient evidence to suggest that the hypersensitivity of sexually satiated males to drugs would include crude extracts. This question lies outside of the aim of our study, but it is possible to explain that, at least $\mathrm{Td}$ (the same employed herein) produces prosexual effects in sluggish or SExh male rats, but the former responded at lower doses $(10 \mathrm{mg} / \mathrm{kg})$ than sexually satiated males $(80 \mathrm{mg} / \mathrm{kg})$ on the same schedule $[9,10]$. Also, it has been demonstrated that the standardized extracts used herein ( $\mathrm{Cm}$ and $\mathrm{Td}$ ) administered acutely $(1,000-5,000 \mathrm{mg} / \mathrm{kg})$ lacked effects on general locomotor activity, and only $\mathrm{Cm}$ at $5,000 \mathrm{mg} / \mathrm{kg}$ produced hyperactivity, kinking, and bristling tail in nonsexually experienced males $[10,21]$. These elements were useful to determine that the effects of $\mathrm{Cm}$ and $\mathrm{Td}$ on sexual satiation are not affected by the motor alterations of rats resulting from sexual activity to satiation.

Our previous phytochemical investigations of the aerial parts of $\mathrm{Cm}$ led us to obtain a number of secondary metabolites; many of these are flavonoids in relatively high abundance $[21,22]$. Flavonoids have many beneficial biological actions [9], among these prosexual effects [34], which could be associated with the synthesis and metabolism of sex hormones. Thus, daidzen, apigenin, and apigenin 7-glucoside (Ap-7-Glc) derivatives mimic the effects of estrogens [35], while flavones like chrysin [36], pinocembrin, and acacetin [37] produce a rise in the concentration of testosterone (T) in in vivo or in vitro models. In this regard, male sexual behavior is importantly stimulated by $\mathrm{T}$ in rats; in addition to $\mathrm{T}$, its estrogenic metabolite, $17 \beta$-estradiol $\left(\mathrm{E}_{2}\right)$, obtained through the aromatization of the androgen by the aromatase enzyme, is crucial for the expression of their sexual behavior [38]. The effects of sex hormones are produced by two mechanisms: steroids bind to intracellular receptors for the production of genomic, long-term effects or interact with the membrane receptor for the induction of short-term effects [39, 40]. Results obtained in the present study could agree with the idea of rapid effects evoked by sex steroids, because the prosexual response was obtained $60 \mathrm{~min}$ after the extracts were administered. However, more research is needed in order to know whether these extracts (or their components) are able to raise sex hormones in a shorter time period.

The most abundant compounds found in the aqueous extract of $\mathrm{Cm}$ are apigenin-7-O- $\beta-\mathrm{D}\left[\left(6^{\prime \prime}-O-p\right.\right.$-coumaroyl $\left.)\right]$ glucoside, Ap-7-( $6^{\prime \prime}$-coumaroyl-Glc), and three regioisomers in relative high abundance $(93.4 \%)$. These latter are produced by an intermolecular rearrangement of $7-\left(6^{\prime \prime}\right.$-coumaroylGlc). Flavonoid glucosides such as Ap-7-(6"-coumaroyl-Glc) are susceptible to hydrolysis, leading first to the formation of apigenin-7-glucoside (Ap-7-Glc) and coumaric acid and then to free apigenin $[41,42]$. It is interesting to note that these labile Ap-7-Glc derivatives are easily degraded to yield free apigenin during the isolation process, whereby these are not usually detected $[10,43]$. In our previous study [21], we isolated, to our knowledge for first time, these Ap-7- $\left(6^{\prime \prime}\right.$ coumaroyl-Glc) from the aqueous extract of C. mexicana, while free apigenin was only detected in trace amounts. Free apigenin is present in several plants and is consistently reported to produce anxiolytic, antidepressant, and prosexual effects $[41,44]$. However, species with anxiolytic activity, such as Matricaria recutita [45], lack prosexual effects. The above suggest that Ap-7-Glc derivatives contribute to the specific prosexual actions of $\mathrm{Cm}$ reported herein, rather than the free apigenin.

Additionally, in the Cm extract, the presence of some phenylpropanoids, such as caffeic and ferulic acids, was detected [21]. The former are proposed to modulate the nitric oxide (NO) pathway in some models of biological activity [46], while ferulic acid has been found to restore the content of brain monoamines in a model of monoamine-depletion in mice elicited by reserpine [47]. These neurotransmitters participate in sexual performance [9] and in the reversal of the sexual exhaustion state $[16,23,29]$. It is important to bear in mind that the phenomenon of sexual exhaustion and its reversal is very complex and is regulated by circuits beyond those participating in the expression of regular sexual behavior [17, 48]. In addition to monoamines and NO, other elements, such as opioids and excitatory aminoacids, take part in this phenomenon, which modulates neuronal 
excitability by different mechanisms downstream in cells [24, $29,49]$. Some of these pathways, such as the NO pathway, have been reported to participate in the prosexual effects of formulations from plants, such as the aqueous extract of $T$. diffusa [9].

In summary, data suggest the following: (1) the prosexual effects described here for $\mathrm{Cm}$ in behavior might be due to the activation of systems of rapid responses, such as neurotransmitters, that is, the catecholamines; (2) the prosexual effects of $\mathrm{Cm}$ are not associated with motor alterations; (3) reversal of the sexual decline is nearly always obtained with pure compounds [11]; thus, the positive results exposed here indicate an important stimulating effect of $\mathrm{Cm}$ on sexual behavior, and (4) the apigenin glycoside derivative, but not in its free form, could be responsible, at least in part, for the prosexual effect of $\mathrm{Cm}$, as well as for that of Td. Specific studies are necessary to support these hypotheses.

In conclusion, the results presented herein demonstrate that $\mathrm{Cm}$, as well as $\mathrm{Td}$, reverses the inhibition of sexual behavior in SExh males. Differences in effective doses for improving the expression of sexual behavior and the properties of C. mexicana on sexual performance should be taken into account by users and traditional physicians, in order to produce the expected benefits.

\section{Competing Interests}

The authors declare that there are no conflicts of interests regarding the publishing of this paper.

\section{Acknowledgments}

The authors wish to express their thanks to Sergio MárquezBaltazar and Alejandra Orellana-Barbosa, B.S., for their technical assistance for animal care and the development of the experiments included in this paper, Roberto Valiente for English language editing, and Dr. Ignacio Camacho-Arroyo for the revision of this manuscript. The present work was financially supported by the Instituto Nacional de Psiquiatría Ramón de la Fuente Muñiz (NC113370.3) in Mexico City, Mexico.

\section{References}

[1] V. Guarner and M. E. Rubio-Ruiz, "Aging, metabolic syndrome and the heart," Aging and Disease, vol. 3, no. 3, pp. 269-279, 2012.

[2] R. Shamloul, "Natural aphrodisiacs," Journal of Sexual Medicine, vol. 7, no. 1, pp. 39-49, 2010.

[3] P. Sandroni, "Aphrodisiacs past and present: a historical review," Clinical Autonomic Research, vol. 11, no. 5, pp. 303-307, 2001.

[4] M. Martínez, Las Plantas Medicinales de México, Ediciones Botas, México City, México, 6th edition, 1996.

[5] P. Goetz, "Traitement des troubles de la libido masculine," Phytothérapie, vol. 4, no. 1, pp. 9-14, 2006.

[6] J. L. Villaseñor and M. R. Redonda-Martínez, "El género Chrysactinia (Asteraceae, tribu Tageteae) en México," Revista Mexicana de Biodiversidad, vol. 80, no. 1, pp. 29-37, 2009.
[7] L. Lappas and C. B. Gustafson, "Investigation of Chrysactinia mexicana, A. Gray," Journal of the American Pharmaceutical Association, vol. 39, no. 10, pp. 591-594, 1950.

[8] R. Arletti, A. Benelli, E. Cavazzuti, G. Scarpetta, and A. Bertolini, "Stimulating property of Turnera diffusa and Pfaffia paniculata extracts on the sexual behavior of male rats," Psychopharmacology, vol. 143, no. 1, pp. 15-19, 1999.

[9] R. Estrada-Reyes, M. Carro-Juárez, and L. Martínez-Mota, "Pro-sexual effects of Turnera diffusa Wild (Turneraceae) in male rats involves the nitric oxide pathway," Journal of Ethnopharmacology, vol. 146, no. 1, pp. 164-172, 2013.

[10] R. Estrada-Reyes, P. Ortiz-López, J. Gutiérrez-Ortíz, and L. Martínez-Mota, "Turnera diffusa Wild (Turneraceae) recovers sexual behavior in sexually exhausted males," Journal of Ethnopharmacology, vol. 123, no. 3, pp. 423-429, 2009.

[11] A. Fernández-Guasti and G. Rodríguez-Manzo, "Pharmacological and physiological aspects of sexual exhaustion in male rats," Scandinavian Journal of Psychology, vol. 44, no. 3, pp. 257-263, 2003.

[12] F. A. Beach and R. G. Rabedeau, "Sexual exhaustion and recovery in the male hamster," Journal of Comparative and Physiological Psychology, vol. 52, no. 1, pp. 56-61, 1959.

[13] D. W. H. Cohn, R. S. Tokumaru, and C. Ades, "Female novelty and the courtship behavior of male guinea pigs (Cavia porcellus)," Brazilian Journal of Medical and Biological Research, vol. 37, no. 6, pp. 847-851, 2004.

[14] C. Villagrán, J. Navarro, and V. O. Fuentes, "Sexual exhaustion in White New Zealand male rabbits of different ages," Animal Reproduction Science, vol. 76, pp. 251-255, 2003.

[15] C. H. Phoenix and K. C. Chambers, "Old age and sexual exhaustion in male rhesus macaques," Physiology and Behavior, vol. 44, no. 2, pp. 157-163, 1988.

[16] G. Rodríguez-Manzo and A. Fernández-Guasti, "Reversal of sexual exhaustion by serotonergic and noradrenergic agents," Behavioural Brain Research, vol. 62, no. 2, pp. 127-134, 1994.

[17] G. Rodríguez-Manzo, K. Larsson, F. Pellicer, and A. FernándezGuasti, "Stimulation of the medial preoptic area facilitates sexual behavior but does not reverse sexual satiation," Behavioral Neuroscience, vol. 114, no. 3, pp. 553-560, 2000.

[18] G. Rodríguez-Manzo and F. Pellicer, "Electrical stimulation of the ventral tegmental area exerts opposite effects on male rat sexual behaviour expression depending on the stimulated sub region," Behavioural Brain Research, vol. 179, no. 2, pp. 310-313, 2007.

[19] F. A. Beach and L. Jordan, "Sexual exhaustion and recovery in the male rat," Quarterly Journal of Experimental Psychology, vol. 8, no. 3, pp. 121-133, 1956.

[20] G. Rodríguez-Manzo, "Yohimbine interacts with the dopaminergic system to reverse sexual satiation: further evidence for a role of sexual motivation in sexual exhaustion," European Journal of Pharmacology, vol. 372, no. 1, pp. 1-8, 1999.

[21] J. Cassani, O. A. Ferreyra-Cruz, A. M. Dorantes-Barrón, R. M. Vigueras Villaseñor, D. Arrieta-Baez, and R. Estrada-Reyes, "Antidepressant-like and toxicological effects of a standardized aqueous extract of Chrysactinia mexicana A. Gray (Asteraceae) in mice," Journal of Ethnopharmacology, vol. 171, pp. 295-306, 2015.

[22] O. A. Ferreyra-Cruz, Caracterización química de un extracto acuoso de Chrysactinia mexicana (Asteraceae) y evaluación de su efecto afrodisíaco en ratas macho [M.S. thesis in Sciences], Universidad Autónoma Metropolitana, Mexico City, México, 2016. 
[23] G. Rodríguez-Manzo and A. Fernández-Guasti, "Participation of the central noradrenergic system in the reestablishment of copulatory behavior of sexually exhausted rats by yohimbine, naloxone, and 8-OH-DPAT," Brain Research Bulletin, vol. 38, no. 4, pp. 399-404, 1995.

[24] G. Rodríguez-Manzo, "Glutamatergic transmission is involved in the long lasting sexual inhibition of sexually exhausted male rats," Pharmacology Biochemistry and Behavior, vol. 131, pp. 6470, 2015.

[25] A. J. Bella and R. Shamloul, "Traditional plant aphrodisiacs and male sexual dysfunction," Phytotherapy Research, vol. 28, no. 6, pp. 831-835, 2014.

[26] M. D. Waldinger and B. Olivier, "Animal models of premature and retarded ejaculation," World Journal of Urology, vol. 23, no. 2, pp. 115-118, 2005.

[27] G. Rodríguez-Manzo and A. Fernández-Guasti, "Opioid antagonists and the sexual satiation phenomenon," Psychopharmacology, vol. 122, no. 2, pp. 131-136, 1995.

[28] B. V. Phillips-Farfán and A. Fernández-Guasti, "Endocrine, neural and pharmacological aspects of sexual satiety in male rats," Neuroscience \& Biobehavioral Reviews, vol. 33, no. 3, pp. 442-455, 2009.

[29] I. L. Guadarrama-Bazante, A. Canseco-Alba, and G. RodríguezManzo, "Dopamine receptors play distinct roles in sexual behavior expression of rats with a different sexual motivational tone," Behavioural Pharmacology, vol. 25, no. 7, pp. 684-694, 2014.

[30] J. Rojas-Hernández and J. Juárez, "Copulation is reactivated by bromocriptine in male rats after reaching sexual satiety with a same sexual mate," Physiology \& Behavior, vol. 151, pp. 551-556, 2015.

[31] Q. J. A. Villarreal, "Familia compositae. Tribu tageteae," in Flora del Bajío y de Regiones Adyacentes, J. Rzedowski and G. Calderón, Eds., Fascículo 113, Instituto de Ecología A.C., Pátzcuaro, Mexico, 2003.

[32] J. B. Mitchell and A. Gratton, "Involvement of mesolimbic dopamine neurons in sexual behaviors: implications for the neurobiology of motivation," Reviews in the Neurosciences, vol. 5, no. 4, pp. 317-329, 1994.

[33] G. Rodríguez-Manzo, I. L. Guadarrama-Bazante, and A. Morales-Calderón, "Recovery from sexual exhaustion-induced copulatory inhibition and drug hypersensitivity follow a same time course: two expressions of a same process?" Behavioural Brain Research, vol. 217, no. 2, pp. 253-260, 2011.

[34] N. Malviya, S. Jain, V. B. Gupta, and S. Vyas, "Recent studies on aphrodisiac herbs for the management of male sexual dysfunction-a review," Acta Poloniae Pharmaceutica-Drug Research, vol. 68, no. 1, pp. 3-8, 2011.

[35] S. A. Whitehead and S. Rice, "Endocrine-disrupting chemicals as modulators of sex steroid synthesis," Best Practice and Research: Clinical Endocrinology and Metabolism, vol. 20, no. 1, pp. 45-61, 2006.

[36] O. Ciftci, I. Ozdemir, M. Aydin, and A. Beytur, "Beneficial effects of chrysin on the reproductive system of adult male rats," Andrologia, vol. 44, no. 3, pp. 181-186, 2012.

[37] J. Zhao, A. K. Dasmahapatra, S. I. Khan, and I. A. Khan, "Antiaromatase activity of the constituents from Damiana (Turnera diffusa)," Journal of Ethnopharmacology, vol. 120, no. 3, pp. 387393, 2008

[38] G. Morali, K. Larsson, and C. Beyer, "Inhibition of testosteroneinduced sexual behavior in the castrated male rat by aromatase blockers," Hormones and Behavior, vol. 9, no. 3, pp. 203-213, 1977.

[39] M. Beato, "Gene regulation by steroid hormones," Cell, vol. 56, no. 3, pp. 335-344, 1989.

[40] C. S. Watson and C. A. Lange, "Steadying the boat: integrating mechanisms of membrane and nuclear-steroid-receptor signalling," EMBO Reports, vol. 6, no. 2, pp. 116-119, 2005.

[41] S. Kumar and A. Sharma, "Apigenin: the anxiolytic constituent of Turnera aphrodisiaca," Pharmaceutical Biology, vol. 44, no. 2, pp. 84-90, 2006.

[42] D. L. McKay and J. B. Blumberg, "A review of the bioactivity and potential health benefits of chamomile tea (Matricaria recutita L.)," Phytotherapy Research, vol. 20, no. 7, pp. 519-530, 2006.

[43] V. Švehlíková, R. N. Bennett, F. A. Mellon et al., "Isolation, identification and stability of acylated derivatives of apigenin 7-O-glucoside from chamomile (Chamomilla recutita [L.] Rauschert)," Phytochemistry, vol. 65, no. 16, pp. 2323-2332, 2004.

[44] S. Kumar, R. Madaan, and A. Sharma, "Estimation of apigenin, an anxiolytic constituent, in Turnera aphrodisiaca," Indian Journal of Pharmaceutical Sciences, vol. 70, no. 6, pp. 847-851, 2008.

[45] H. Viola, C. Wasowski, M. Levi De Stein et al., "Apigenin, a component of Matricaria recutita flowers, is a central benzodiazepine receptors-ligand with anxiolytic effects," Planta Medica, vol. 61, no. 3, pp. 213-216, 1995.

[46] T. Silva, C. Oliveira, and F. Borges, "Caffeic acid derivatives, analogs and applications: a patent review (2009-2013)," Expert Opinion on Therapeutic Patents, vol. 24, no. 11, pp. 1257-1270, 2014.

[47] Y. Xu, L. Zhang, T. Shao et al., "Ferulic acid increases pain threshold and ameliorates depression-like behaviors in reserpine-treated mice: behavioral and neurobiological analyses," Metabolic Brain Disease, vol. 28, no. 4, pp. 571-583, 2013.

[48] G. Rodríguez-Manzo and F. Pellicer, "Electrical stimulation of dorsal and ventral striatum differentially alters the copulatory behavior of male rats," Behavioral Neuroscience, vol. 124, no. 5, pp. 686-694, 2010.

[49] R. Garduño-Gutiérrez, L. Guadarrama-Bazante, M. León-Olea, and G. Rodríguez-Manzo, "Endogenous opioids mediate the sexual inhibition but not the drug hypersensitivity induced by sexual satiation in male rats," Behavioral Neuroscience, vol. 127, no. 3, pp. 458-464, 2013. 

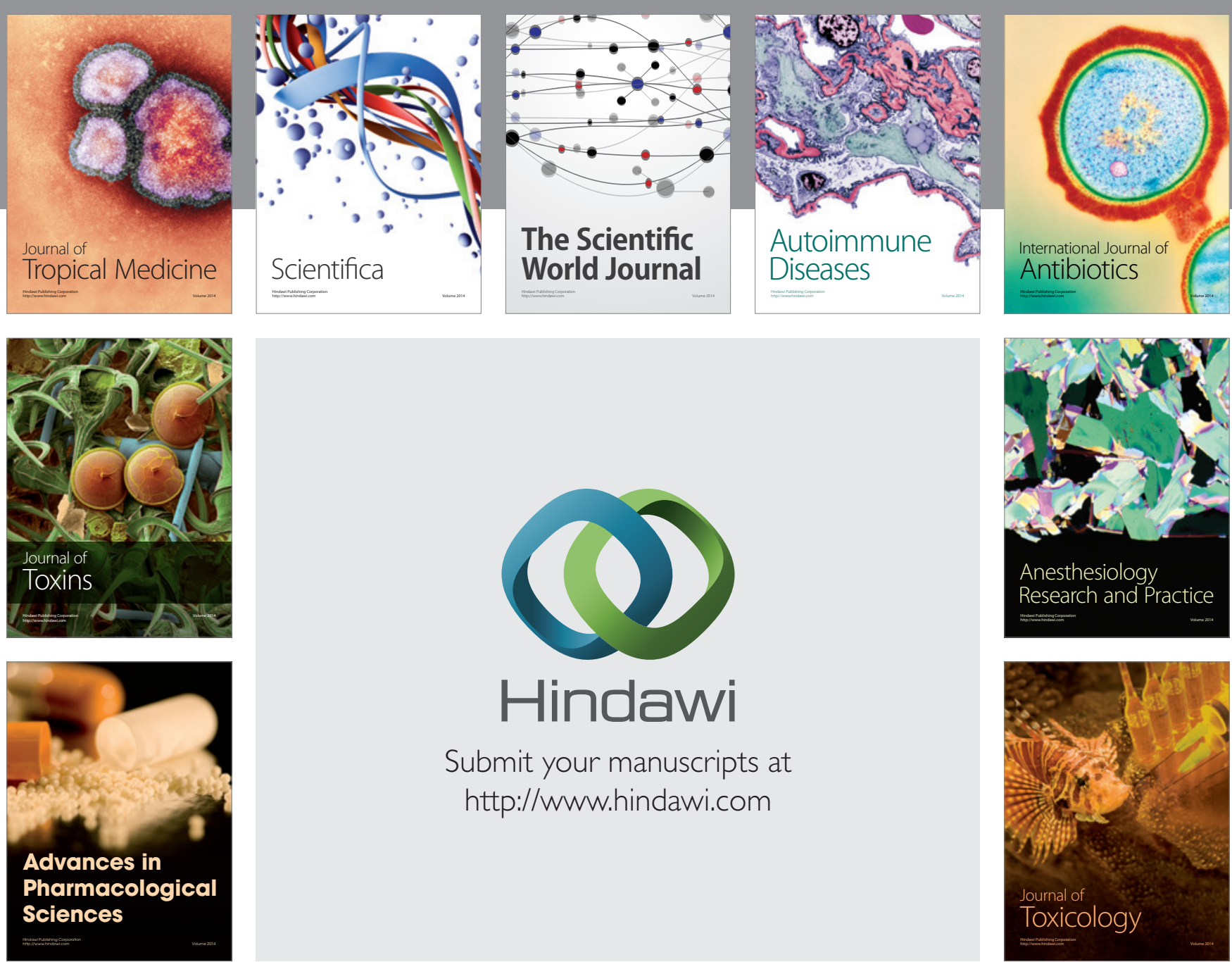

\section{Hindawi}

Submit your manuscripts at

http://www.hindawi.com
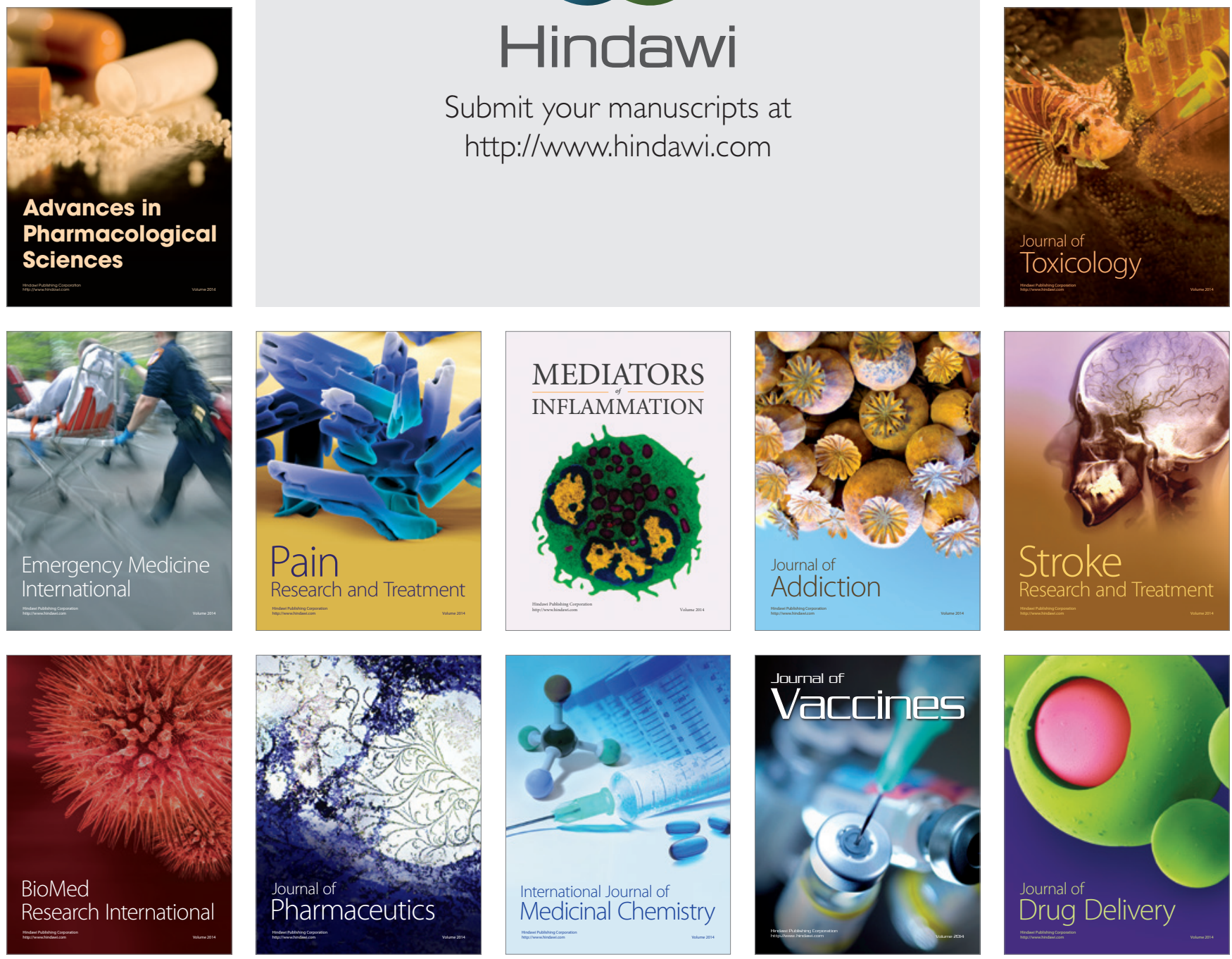